\title{
黑龙江省肖叶甲科种类及地理分布
}

\author{
李兴鹏 ${ }^{1}$, 李成德 ${ }^{2,}$, 宋丽文 ${ }^{1}$, 陈越渠 ${ }^{1}$, 王永显 ${ }^{1}$ \\ (1. 吉林省林业科学研究院, 吉林 长春 130033；2. 东北林业大学 林学院, 黑龙江 哈尔滨 150040)
}

摘要: 2005 年 4 月-2007 年 10 月对黑龙江省肖叶甲科的种类及地理分布进行了调查, 并根据中国动物地理 分区方法, 将黑龙江省肖叶甲动物地理分为 11 个省级区划单元; 并根据其的分布记录, 构成 $\mathrm{C}$ 数据矩阵, 采用 最大值法进行聚类运算。结果共记录肖叶甲 14 属 57 种（亚种）, 其中包括隐头叶甲亚科 34 种、锯角叶甲亚科 15 种、肖叶甲亚科 8 种, 分别占总数的 $59.6 \%$ 、26.3\%和 $14.1 \%$ 。其他两亚科即隐肢叶甲亚科和瘤叶甲亚科在黑 龙江省无分布。在区系成分上有 3 属共 9 种只在古北区分布, 属于古北种; 1 种为黑龙江省特有种; 其他在古北、 东洋两区均有分布, 属于广布种。统计分析发现本科的大多数种类均分布于该省东南部, 气候较温和湿润的区域。 其中东南山区, 包括牡丹江东部和西部, 共有 41 种, 占总数的 $71.9 \%$; 其次是松嫩平原地区 22 种和兴安岭山区 15 种, 分别占总数的 $38.6 \%$ 和 $26.3 \%$ 。聚类分析结果与地理区划结果基本吻合, 第一组即牡丹江西部省与牡丹江 东部省关系最为密切, 第二组松江平原省与松嫩北部省关系最近, 而西部干旱草原省与其他各省关系最远。

关键词: 肖叶甲科; 区系成分; 地理分布; 黑龙江省

中图分类号：Q969.48 文献标识码：A 文章编号：0254-5853-(2008)04-0438-09

\section{Faunistic and Distribution of Eumolpidae (Coleoptera: Chrysomeloidea) Species in Heilongjiang Province, China}

\author{
LI Xing-peng ${ }^{1}$, LI Cheng-de ${ }^{2, *}$, SONG Li-wen ${ }^{1}$, CHEN Yue-qu ${ }^{1}$, WANG Yong-yu ${ }^{1}$ \\ (1. Jilin Provincial Academy of Forestry Sciences, Changchun 130033, China; \\ 2. College of Forestry, Northeast Forestry University, Harbin 150040, China)
}

\begin{abstract}
Surveys were conducted to study faunistic and distribution of Eumolpidae species in Heilongiang Province between April 2005 and October 2007. Fauna of Eumolpidae in Heilongjiang Province were first divided into 11 geographic sub-regions based on the principles of zoogeographic distribution in China and using distribution records of Eumolpidae species in 11 geographic sub-regions, a $\mathrm{C}$ matrix was constructed then a clustering analysis maximum value method was used. A total of 57 species (subspecies) belonging to 14 genera were recorded, including, Cryptocephalinae, Clytrinae, and Eumolpinae, 34 species (accounting for 59.6\% of the total), 15 species (26.3\%), and 8 species (14.1\%) respectively. Species of Lamprosomatinae and Chlamisinae have not been found in Heilongjiang Province. Only nine species (belonging to three genera) are distributed in the Palearctic Region and one species is endemic to Heilongjiang Province. The others are widely distributed in the Palearctic and Oriental Region. The analysis indicated that $71.9 \%$ of the total species ( 41 species) are distributed in the southeast of the Province, where the climate is warmer and more humid than other regions. Fifteen and 22 species found in Xing'an Mountain and Songnen Plain, account for $26.3 \%$ and $38.6 \%$ of the total number of species respectively. The clustering analysis of region similarity of Eumolpidae demonstrated that the closest relationship was between the western and eastern parts of Mudanjiang Region, then Songjiang Plain Region and Northern Songnen Region. The western dry grasslands region had the most alienated relationship with the others.
\end{abstract}

Key words: Eumolpidae; Faunal component; Geographical distribution; Heilongjiang Province 
黑龙汇省地处北纬 $43^{\circ} 25^{\prime}-53^{\circ} 33^{\prime}$, 东经 $121^{\circ} 11^{\prime}-135^{\circ} 5^{\prime}$, 南北长 $1000 \mathrm{~km}$, 是我国最北 省份。地域辽阔, 地势复杂, 西部有大、小兴安岭; 东南部有张广才岭和老爷岭等几列平行山脉, 海拔 $600 \mathrm{~m}$ 以上; 西、北尚有许多沼泽、湿地; 东北端 和西向有三江平原与松嫩平原, 海拔 $80-200 \mathrm{~m}$ 。 气候属中温带, 在 $-4-4{ }^{\circ} \mathrm{C}$ 之间, 各地气候差异显 著, 从东南向西北显著递减, 植被类型复杂多样, 为肖叶甲的栖息繁衍提供了多种生境。

肖叶甲科隶属于鞘翅目多食亚目叶甲总科, 包 括 5 个亚科: 肖叶甲亚科 (Eumolpinae)、隐肢叶 甲亚科（Lamprosomatinae）、瘤叶甲亚科

(Chlamisinae) 、锯角叶甲亚科 (Clytrinae) 和隐 头叶甲亚科 (Cryptocephalinae), 广泛分布于世界 六大动物区系, 但以热带、亚热带分布居多。目前, 世界已记录 9000 多种, 中国已记述 700 余种（Tan et al, 2005)。

肖叶甲科昆虫个体大小差异较大, 一般为 $2-8$ $\mathrm{mm}$, 体型有圆柱形、卵圆形、长方形或五边形; 一般多具鲜艳的金属色泽。本科的很多种类成虫主 要取食寄主植物的叶片、叶柄、嫩梢或嫩枝的皮层 等, 幼虫生活于土中, 取食植株根部, 并于土中化 蛹羽化, 危害林木以及农作物。

自 Latreille(1802-1805)首次建立叶甲科, 肖叶 甲科已有 200 多年的分类历史。早期的工作主要停 留在新分类单元的发现和描述阶段, 也进行了部分 总结工作。国内陈世骧先生从 1934 年起即开始对 本科种类的系统研究, 发现了大量新种, 并提出肖 叶甲亚科应与隐肢叶甲、瘤叶甲、锯角叶甲和隐头 叶甲四亚科组成一个科（Chen, 1934）。此后国内 外许多学者对中国肖叶甲进行了大量研究, 并不断 对叶甲系统进行完善, 陆续发表新属、新种以及系 统发育和区系分析等专著或论文 (Gressitt \& Kimoto, 1961; Lopatin, et al, 2004; Tan et al, 1980, 2005, Tan \&Wang, 1981; Chen, 1935, 1992; Chen et al, 1976; Tan, 1994; Yang, 1997, 2004, 2005; Zhou, 1997, 1999a, b) 。

由于本科种类丰富度从南到北急剧减少, 因此 在很长时间内, 学者对黑龙江省肖叶甲科种类研究 相对薄弱。但是, 作为一个生物类群, 它必然起源 于叶甲祖系, 而又具有自身特有的生物学特征, 与 叶甲有着进化上的间断性与连续性的对立统一
(Chen, 1961)。为了正确地反映出肖叶甲类群与其他 地区叶甲的潜在系谱关系和历史演化过程, 并由此 探索间断性的起源和发展规律, 并最终为该科的系 统发育学、分子生物学、生理学、解剖学等提供完 整而可靠的基础资料，

作者通过调查, 结合以往肖叶甲科标本对黑龙 江省肖叶甲科区系及地理分布进行了统计分析, 提 出我省比较合理的肖叶甲科昆虫地理区划, 并总结 分析了各区系种类组成的分异特点。

\section{1 材料和方法}

所研究和鉴定的肖叶甲标本, 除部分借自东北 林业大学昆虫标本室 50 多年的馆藏标本外, 其余 为作者在 2005-2007 年间的采集积累。

\section{1 动物地理分区}

根据黑龙江省自然环境条件、动物区系组成、 动物类群的不等值、同周边国家的联系和生产实践 五项区划原则( Hu et al, 2006), 并参照黑龙江省动物 地理区划已有的研究成果(Zhang, 1998，1999; Fang, 1993)，作者将该省动物地理分为 2 亚区、4地区和 11 个省级区划单元(表1)。

\section{2 标本采集地点及时间确定}

按照上述动物地理分区, 分别设置11个采集 区, 并按照肖叶甲生物学习性, 自2005至2007连续 3 年, 于每年 4 月中旬到 10 月末, 分成3组, 分别在 不同采集地区，每15天采集一次。

\section{3 标本记录}

对所采集标本根据有关文献逐一鉴定 (Gressitt \& Kimoto, 1961; Warchalowski, 2003; Lopatin, et al, 2004; Bienkowski, 2004; Hurka, 2005; Tan et al, 1980, 2005），并记录其分布地，未能镜检标本则依据文 献确定其分布地, 最后按照地理分区确定其归属。

\section{4 数据处理}

将黑龙江省肖叶甲在 11 个省级区划单元的分 布编成“ 0,1 ”分布的二元数据, 构成原始数据矩阵。

在原始数据矩阵的基础上, 计算 $\mathrm{C}$ 数据矩阵, 即共有物种数矩阵(表 3)。又在 $\mathrm{C}$ 数据矩阵的基础 上, 根据相似性系数公式, 计算出任意两地理区划 单元之间的相似性系数, 构成相似性系数矩阵 ( $R$ 数据矩阵) (表 4)。两区域之间的区系相似性系数 (similarity coefficient) 采用 Zhou(1999) 改进的 Udvardy (1969) 公式进行计算, 公式为: $R_{i j}=100 \times$ 
$C_{i j} /\left(C_{i i}+C_{j j}-C_{i j}\right)$, 式中 $R_{i j}$ 为任意两个区域之间的区 系相似性系数, $C_{i i}$ 为 $i$ 区域内的种数, $C_{j j}$ 为 $\mathrm{j}$ 区域 内的种数, $C_{i j}$ 为 $i$ 区与 $j$ 区之间的共有种数。根据 $R_{i j}$ 值越大, 两地区关系程度愈高的原则, 采用最大 值法(Sneath \& Sokal, 1973)进行聚类运算。

\section{2 结 果}

\section{1 种类组成及区系成分}

在本研究的 57 个种类中（附表 1)（包括 3 新 种, 2 中国新记录种, 另文发表), 隐头叶甲亚科 种类最为丰富, 共计 34 种, 占总数的 $59.6 \%$; 锯角 叶甲亚科 15 种, 占 $26.3 \%$; 肖叶甲亚科最少, 共计 8 种, 占 $14.1 \%$; 其他两亚科即隐肢叶甲亚科和瘤 叶甲亚科在黑龙江省无分布。在区系成分上只有 3 属共 9 种只在古北区分布, 属于古北种; 1 种为黑 龙江省特有种; 其他均在古北、东洋两区都有分布, 属于广布种（表 2）。

\section{2 区域分化}

在黑龙江省本科的大多数种类均分布于东南 部, 气候较温和湿润的区域（附表 1)。其中东南 山区, 包括牡丹江东部和西部, 共有肖叶甲 41 种, 占总数的 $71.9 \%$; 其次是兴安岭山区 15 种和松嫩平 原地区 22 种, 分别占总数的 $26.3 \%$ 和 $38.6 \%$ 。

\section{3 区域相似性}

采用最大值法进行聚类运算, 结果如图 1 所
示。

该聚类分析结果与我们做的黑龙江省的地理 区划结果基本吻合。第一组即牡丹江西部省与牡丹 江东部省关系最为密切, 其次是小兴安岭; 第二组 松江平原省与松嫩北部省关系最近，而松嫩东部山 边省也与前二者具有高的相似性。西部干旱草原省 与其他各省关系最远。

\section{3 讨 论}

根据各种资料统计, 与黑龙江省地理位置、气 候相似的俄罗斯远东及西伯利亚地区肖叶甲种类 为 97 种，但本次研究只采集鉴定出肖叶甲种类 57 种。这可能是由于远东地区与黑龙江省的植被类型 存在着差异而导致两地区肖叶甲种类存在差异。另 外, 俄罗斯的肖叶甲科分类研究已经有几百年的历 史, 标本的采集鉴定及分类研究已经十分深入, 但 我国该科的分类研究于 1934 年才开始 (Chen, 1935），黑龙江地区更是上世纪 50 年代才展开, 而本研究是从 2004 年开始进行的。由于该科种类 生境比较隐蔽, 在短时间内不可能无遗漏地采集到 所有种类, 这也可能是只鉴定出 57 种 (亚种) 的 原因。随着标本的采集积累, 可能还有更多该科种 类被发现。

表 1 黑龙江动物地理区划分级

Tab. 1 Division of zoogeographical regions in Heilongjiang

\begin{tabular}{|c|c|c|c|}
\hline 0 级 0 class & 00 级 00 class & $\mathrm{I}$ 级 $\mathrm{I}$ class & II 级 II class \\
\hline 古北区 & （一）欧洲-西伯利亚亚区 & I. 兴安岭山区 & $I_{1}$. 大兴安岭省 \\
\hline \multirow[t]{13}{*}{ Palaearctic Region } & Europe-Siberia Subregion & Xing'an Mountains & Daxing'an Mountain Region \\
\hline & & & I 2.小兴安岭省 Xiaoxing'an Mountain Region \\
\hline & (二) 中国东北亚区 & II.三江平原区 & $\mathrm{II}_{1}$.三江东部省 \\
\hline & Northeast of China Subregion & Sanjiang Plain & Eastern Sanjiang Region \\
\hline & & & $\mathrm{II}_{2}$.完达山省 Wandashan Region \\
\hline & & III.东南山区 & $\mathrm{III}_{1}$.牡丹江西部省 \\
\hline & & Southeast Mountains & Western Mudanjiang Region \\
\hline & & & $\mathrm{III}_{2}$.牡丹江东部省 Eastern Mudanjiang Region \\
\hline & & IV.松嫩平原区 Songnen Plain & $I_{1}$. 松嫩东部山边省 Eastern Songnen Region \\
\hline & & & $\mathrm{IV}_{2}$. 松江平原省 Songjiang plain Region \\
\hline & & & $\mathrm{IV}_{3}$.松嫩北部省 Northern Songnen Region \\
\hline & & & $\mathrm{IV}_{4}$.西部盐碱土省 Western salinization soil Region \\
\hline & & & $\mathrm{IV}_{5}$.西部干早草原省 Western dry grasslands Region \\
\hline
\end{tabular}


表 2 黑龙江省肖叶甲科各属在中国地理区划中的分布

Tab.2 Faunal components of Eumolpid genera in Heilongjiang Province

\begin{tabular}{|c|c|c|c|c|c|c|c|c|}
\hline \multirow{2}{*}{$\begin{array}{c}\text { 亚科及属名 } \\
\text { Subfamily and genera }\end{array}$} & \multirow{2}{*}{$\begin{array}{c}\text { 种数 } \\
\text { Species number }\end{array}$} & \multicolumn{4}{|c|}{ 古北区 Palaearctic Region } & \multicolumn{3}{|c|}{ 东洋区 Oriental Region } \\
\hline & & 东北区 & 华北区 & 蒙新区 & 青藏区 & 西南区 & 华中区 & 华南区 \\
\hline \multicolumn{9}{|l|}{ Eumolpinae } \\
\hline Basilepta & 1 & $\bullet$ & $\bullet$ & & & $\bullet$ & & $\bullet$ \\
\hline Colasposoma & 1 & $\bullet$ & $\bullet$ & $\bullet$ & $\bullet$ & $\bullet$ & $\bullet$ & $\bullet$ \\
\hline Bromius & 1 & $\bullet$ & $\bullet$ & $\bullet$ & $\bullet$ & $\bullet$ & $\bullet$ & $\bullet$ \\
\hline Chrysochus & 1 & $\bullet$ & $\bullet$ & $\bullet$ & $\bullet$ & & $\bullet$ & $\bullet$ \\
\hline Pagria & 1 & $\bullet$ & $\bullet$ & & & $\bullet$ & $\bullet$ & $\bullet$ \\
\hline Parnops & 1 & $\bullet$ & & & & & & \\
\hline Cleoporus & 1 & $\bullet$ & $\bullet$ & & & $\bullet$ & $\bullet$ & $\bullet$ \\
\hline Abiromorphus & 1 & $\bullet$ & $\bullet$ & & & & & $\bullet$ \\
\hline \multicolumn{9}{|l|}{ Clytrinae } \\
\hline Labidostomis & 5 & $\bullet$ & $\bullet$ & $\bullet$ & & & & \\
\hline Cotocephala & 1 & $\bullet$ & $\bullet$ & $\bullet$ & $\bullet$ & & & \\
\hline Clytra & 3 & $\bullet$ & $\bullet$ & $\bullet$ & & & $\bullet$ & $\bullet$ \\
\hline Smaragdina & 5 & $\bullet$ & $\bullet$ & $\bullet$ & & $\bullet$ & $\bullet$ & $\bullet$ \\
\hline \multicolumn{9}{|l|}{ Cryptocephalinae } \\
\hline Cryptocephalus & 32 & $\bullet$ & $\bullet$ & $\bullet$ & $\bullet$ & $\bullet$ & $\bullet$ & $\bullet$ \\
\hline Pachybrachys & 3 & $\bullet$ & $\bullet$ & $\bullet$ & & & & \\
\hline
\end{tabular}

东北区 Northeast Region; 华北区 North China Region; 蒙新区 Mongolia-Xinjiang Region; 青藏区 Qinghai-Tibet Region; 西 南区 Southwest Region; 华中区 Central China Region; 华南区 South China Region。

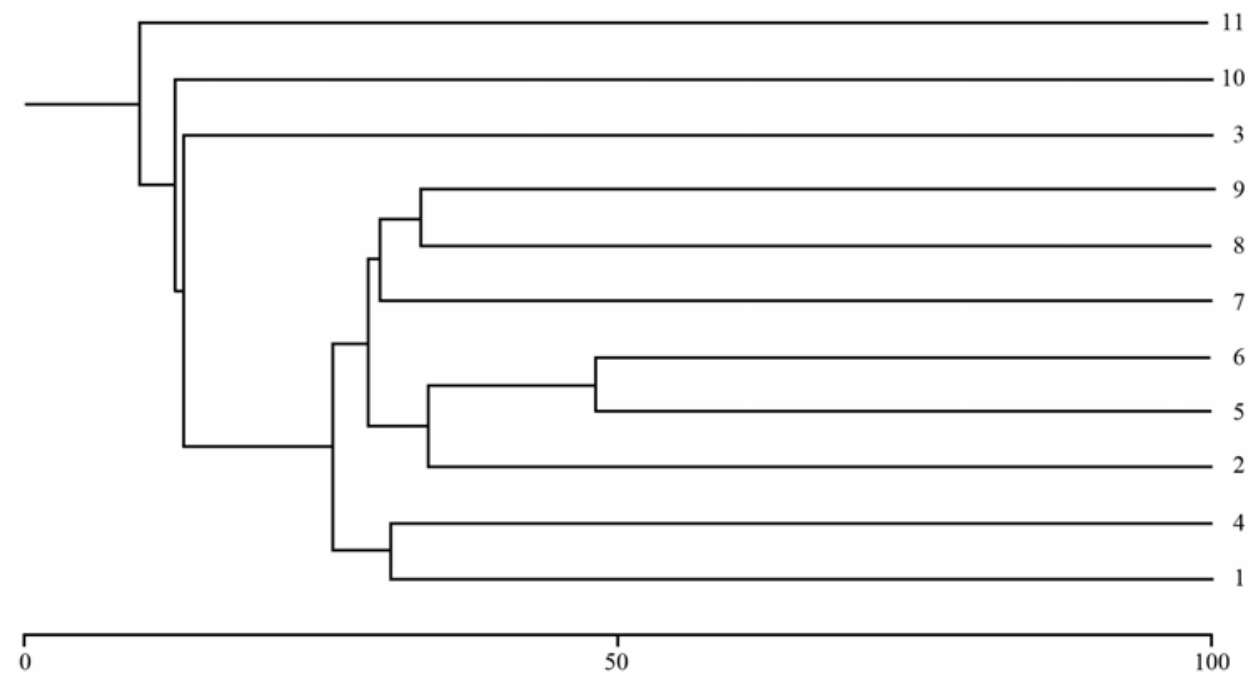

图 1 黑龙江省肖叶甲区域相似性聚类运算结果

Fig. 1 Clustering analysis of region similarity of Heilongjiang Eumolpidae

1-11 分别代表本研究的 11 个地理分区: 大兴安岭省、小兴安岭省、三江东部省、完达山省、牡丹江西部省、牡丹江东部省、 松嫩东部山边省、松江平原省、松嫩北部省、西部盐碱土省和西部干旱草原省。

1-11denote the eleven different Region: Daxing'an Mountain Region, Xiaoxing'an Mountain Region, Eastern Sanjiang Region, Wandashan Region, Western Mudanjiang Region, Eastern Mudanjiang Region, Eastern Songnen Region, Songjiang plain Region, Northern Songnen Region, Western salinization soil Region and Western dry grasslands Region. 
表 3 黑龙江省 11 个地理区划单元的肖叶甲种数和各单元间共有种数 (C 数据矩阵)

Tab. 3 Species of Eumolpidae in 11 geographic regions of Heilongjiang and their similarities

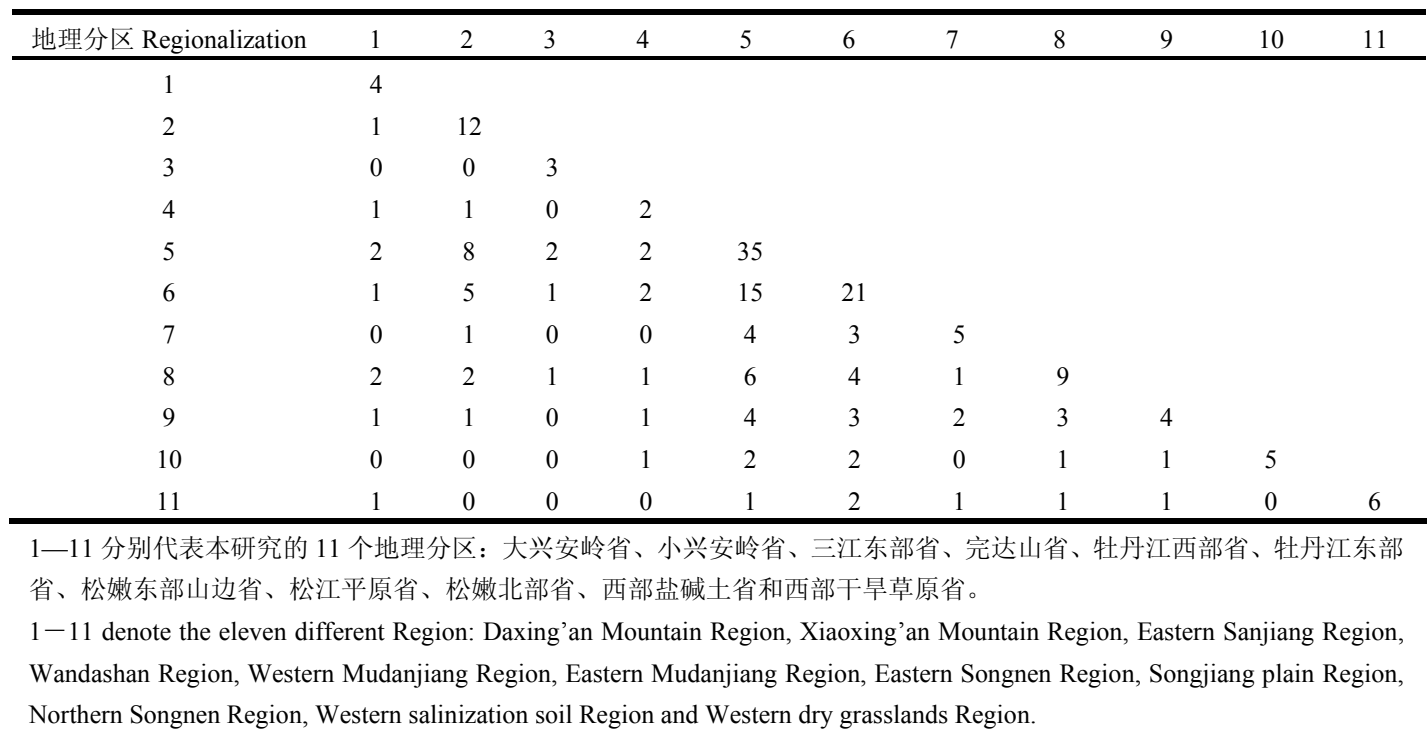

表 4 黑龙江省肖叶甲科区系相似性系数矩阵 ( $R$ 数据矩阵)

Tab. 4 Data matrix of fauna similarity of Eumolpidae in Heilongjiang Province

\begin{tabular}{crrrrrrrrrrr}
\hline 地理分区 Regionalization & 1 & 2 & 3 & 4 & 5 & 6 & 7 & 8 & 9 & 10 \\
\hline 1 & 1.00 & & & & & & & & & \\
2 & 0.07 & 1.00 & & & & & & & \\
3 & 0.00 & 0.00 & 1.00 & & & & & & \\
4 & 0.20 & 0.08 & 0.00 & 1.00 & & & & & & \\
5 & 0.05 & 0.21 & 0.06 & 0.06 & 1.00 & & & & & \\
6 & 0.04 & 0.15 & 0.04 & 0.10 & 0.37 & 1.00 & & & & \\
7 & 0.00 & 0.06 & 0.00 & 0.00 & 0.11 & 0.13 & 1.00 & & \\
8 & 0.18 & 0.11 & 0.09 & 0.10 & 0.16 & 0.15 & 0.08 & 1.00 & & \\
9 & 0.14 & 0.07 & 0.00 & 0.20 & 0.11 & 0.14 & 0.29 & 0.30 & 1.00 & \\
10 & 0.00 & 0.00 & 0.00 & 0.17 & 0.05 & 0.08 & 0.00 & 0.08 & 0.13 & 1.00 \\
11 & 0.11 & 0.00 & 0.00 & 0.00 & 0.03 & 0.08 & 0.10 & 0.07 & 0.11 & 0.00 & 1.00 \\
\hline
\end{tabular}

1-11 分别代表本研究的 11 个地理分区: 大兴安岭省、小兴安岭省、三江东部省、完达山省、牡丹江西部省、牡丹江东部省、松 嫩东部山边省、松江平原省、松嫩北部省、西部盐碱土省和西部干早草原省。

1-11 denote the eleven different Region: Daxing'an Mountain Region, Xiaoxing'an Mountain Region, Eastern Sanjiang Region, Wandashan Region, Western Mudanjiang Region, Eastern Mudanjiang Region, Eastern Songnen Region, Songjiang plain Region, Northern Songnen Region, Western salinization soil Region and Western dry grasslands Region.

兴安岭山区具有典型的高寒植被类型, 而这种 特殊的植物种类将决定该地区特殊的肖叶甲科种 类和分布, 然而本次调查却只有一种属于该地区特 有种类，仅 9 种属于古北种，其种类差别并未表现 在区域分化上。这与大气 $\mathrm{CO}_{2}$ 浓度升高, 全球气候 变暖而引起植被类型的变化（Yi \& Wang，1992） 不无关系。黑龙江省地处中、高纬度, 是近 20 年 气候显著变暖的区域之一(Sha et al, 2002; Pan et al, 2003)。据气象资料显示, 在过去近 30 年（19792000 年) 温度增高 $1.5^{\circ} \mathrm{C}$, 年降雪量下降, 春天冰 雪融化时间提前（Hansen et al, 1999）。我们很早
就知道在全球水平上，气候的变化与植物类群之间 具有高度一致性（Odum, 1983）。气候因素是决定 植物分布范围的决定性因素之一, 有研究指出在全 球范围内当温度每变化 $0.5^{\circ} \mathrm{C}$, 就会引起植被类型 的轻微改变，而且这种改变是成几何基数增加的 （Brovkin et al, 1997）。黑龙江省被认为是全球变 暖的指性地区(Chase et al, 2000), 在这一区域温度 将成为决定植物光合速率的最重要气候因素 $(\mathrm{Yu}$ et al, 2003)。因此温度的细微变化也能引起该地区植 物种类组成及分布的大幅改变, 这种改变将直接影 响当地的生物多样性及生物地理分布，尤其对于一 
些食性专一和生境适应范围较窄的昆虫, 必然引起 许多种类的迁入或迁出。

肖叶甲科作为叶甲类昆虫中种类最为繁盛的 一个类群, 在全球气温普遍变暖的背景下, 黑龙江 省温度逐年上升, 该科许多属于东洋区系的种类极 有可能已经扩散到了该省, 而更多的该地区特有种 可能也随着气候和植物分布的变化而趋于消亡。

不管是从地理气候或是植被类型上分析, 牡丹
江西部与牡丹江东部都有极大的一致性, 但事实上 两者之间的共有种数只有 15 种, 这可能与标本的 采集时间和地区的选择，即采集时间和地点的连续 性有很大的关系。另外一个可能的原因是：牡丹江 西部近几十年在其森林周围开垦了大量农田, 这增 加了森林与其他植被类型过渡边缘, 而往往这种生 境具有较高的生物多样性; 而牡丹江东部的人为干 扰却相对较少。

\section{参考文献:}

Bienkowski AO, 2004. Leaf-beetles (Coleoptera: Chrysomelidae) of the Eastern Europe. New Key to Subfamilies, Genera and Species [M]. Moscow: Mikron-print.

Brovkin V, Ganopolski A, Svirezhev Y. 1997. A continuous climate-vegetation classification for use in climate-biosphere studies [J]. Ecological Modelling, 101: 251-261.

Chase TN, Pielke RA, Knaff J, Kittel T, Eastman J. 2000. A comparison of regional trends in 1979-1997 depth-averaged tropospheric temperatures [J]. International Journal of Climatology, 20: 503-518.

Chen SX. 1934. On the Chinese species of the genus Corynodes. Sinensia, 5(5-6): 484-505.

Chen SX. 1935. Study on Chinese Eumolpid Beetles [J]. Sinensia, 6(3): 221-387.

Chen SX. 1961. On the basic conceptions of taxonomy [J]. Acta Entomologica Sinica, 10(4-6): 321-338. [陈世骧. 1961. 分类学的若 干基本概念. 昆虫学报, 10(4-6): 321-338.]

Chen SX. 1992. Insects of the Hengduan Mountains Region [M]. Beijing: Science Press. [陈世骧. 1992. 横断山区昆虫. 北京: 科学出版社.]

Chen SX, Yu PY, Wang SY, Jiang SQ. 1976. New leaf beetles from west China [J] Acta Entomologica Sinica, 19(2): 213-224. [陈世骧, 虞佩 玉, 王书永, 姜胜巧. 1976. 中国西部叶甲新种志. 昆虫学报, 19(2): 213-224.]

Fang SY. 1993. The Eco-geographical Distribution of Forest Pest-insects in the China [M]. Harbin: Northeast Forestry University Press. [方三阳. 1993. 中国森林害虫生态地理分布. 哈尔滨: 东北林业大学出版 社.]

Gressitt JL, Kimoto S. 1961. The Chrysomelidae (Coleopt.) of China and Korea, Part 1 [A]. In: Pacific Insects Monograph 1A [M]. Hawaii: Bernice Press, 1-299.

Hansen J, Ruedy R, Gloscoe J, Sato M. 1999. GISS analysis of surface temperature change $[\mathrm{J}]$. Journal of Geophysical Research, 104: 30997-31022.

Hu HY, Huang RX, Fan ZT, Wu W, Huang S. 2006. Preliminary study on the fauna and distribution of Chrysomelidae [J]. Acta Zootaxonomica Sinica, 31(1): 69-74. [胡红英, 黄人金菳, 范兆田, 吴 卫, 黄 帅. 2006. 新疆叶甲区系及地理分布的初步研究. 动物分类学报, 31(1): 69-74.]

Hurka K, 2005. Beetles of the Czech and Slovak Republics [M]. Zlin: Kabourek Publishing House.

Lopatin IK, Aleksandrovich OR, Konstantinov AS. 2004. Check List of Leaf-Beetles (Coleotera, Chrysomelidae) of the Eastern Europe and Northern Asia [M]. Olsztyn: Olsztyn Press.

Odum EP. 1983. Basic Ecology [M]. Philadelphia: Saunders College Press.

Pan HS, Zhang GH, Xu NP. 2003. A Preliminary analysis of climate warming in Heilongjiang province since the $1980 \mathrm{~s}[\mathrm{~J}]$. Climatic and
Environmental Research, 8(3): 348-355. [潘华盛, 张桂华, 徐南平. 2003. 20 世纪 80 年代以来黑龙江气候变暖的初步分析. 气候与环 境研究, 8 (3): 348-355.]

Sha WY, Shao XM, Huang M. 2002. Temperature change since 1980s in China and its effect on natural area boundary [J]. Sciences in China (Ser. D), 32(4): 317-326. [沙万英, 邵雪梅, 黄 玫. 2002. 20 世纪 80 年代以来中国的气候变暖及其对自然区域界线的影响.中国科 学(D 辑), 32(4): 317-326.]

Sneath PH, Sokal RR. 1973. Numerical Taxonomy, the Principles and Practice of Numerical Classification [M]. San Francisco: WH Freeman Company.

Tan JJ. 1994. On the distribution patterns of the genera of Chinese Eumolpinae (Coleoptera: Eumolpidae)[J]. Wuyi Science Journal, 11: 93-99. [谭娟杰. 1994. 中国肖叶甲亚科属的分布类型. 武夷科学, 11: 93-99.]

Tan JJ, Wang SY, Zhou HZ. 2005. Fauna Sinica Insect Vol. 40 Coleoptera: Eumolpidae. Eumolpinae [M]. Beijing: Science Press. [谭娟杰, 王书 永, 周红章. 2005. 中国动物志昆虫纲鞘翅目: 肖叶甲科, 肖叶甲亚 科. 北京: 科学出版社.]

Tan JJ, Wang SY. 1981. Coleoptera: Eumolpidae [A]. In: The Series of the Scientific Expedition to the Qinghai-Xizang Plateau. Insecte of Xizang, Vol.1 [M]. Beijing: Science Press, 433-456. [谭娟杰, 王书永. 1981. 鞘翅目: 肖叶甲科. 见: 青藏高原科考组. 西藏昆虫. 北京: 科学出版社, 433-456.]

Tan JJ, Yu PY, Li HX, Wang SY, Jiang SQ. 1980. Economic insect fauna of China, Fasc. 18 Coleoptera: Chrysomeloidea ( I ) [M]. Beijing: Science Press, 94-204. [谭娟杰, 虞佩玉, 李鸿兴, 王书永, 姜胜巧. 1980. 中国经济昆虫志第十八册. 鞘翅目叶甲总科 (一). 北京: 科 学出版社, 94-204.]

Warchalowski A, 2003. Chrysomelidae[A]. The Leaf-beetles of Europe and the Mediterrnean Area [M]. Warsaw: Natura optima Dux Foundation.

Yang XK. 1997. Insects of the Three Gorge Reservoir Area of Yangzi River [M]. Chongqing: Chongqing Press, 846-854. [杨星科. 1997. 长江三 峡库区昆虫. 重庆: 重庆出版社, 846-854.]

Yang XK. 2004. Insects from Mt.Shiwangdashan Area of Guangxi [M] Beijing: China Forestry Publishing House, 356-364. [杨星科. 2004. 广西十万大山地区昆虫. 北京: 中国林业出版社, 356-364.]

Yang XK. 2005. Insect Fauna of Middle-West Qinling Range and South Mountains of Gansu Province [M]. Beijing: Science Press, 429-438. [杨星科. 2005. 秦岭西段及甘南地区昆虫. 北京: 科学出版社, 429-438.]

Yi YH, Wang SW. 1992. Global warming sharpened in 1980s. Chinese Science Bulletin [J]. 37(6): 528-531. [衣育红, 王绍武. 1992. 80 年代 全球气候突然变暖. 科学通报, 37(6): 528-531.] 
Yu FF, Kevin P, Price JE, Peijun S. 2003. Response of seasonal vegetation development to climatic variations in eastern central Asia [J]. Remote Sensing of Environment, 87: 42-54.

Zhang RZ. 1999. The Zoogeography of China [M]. Beijing: Science Press. [张荣祖. 1999. 中国动物地理. 北京: 科学出版社.]

Zhang SM. 1998. The geographical distribution of agricultural and forest insect in China[M]. Beijing: China Agriculture Press. [章士美. 1998. 中国农林昆虫地理区划. 北京: 中国农业出版社.]

Zhou HZ. 1997. Faunistic notes and three new species of Eumolpidae from Fujian Province, China [J]. Acta Zootaxonomica Sinica, 22(2): 189-197.
Zhou HZ, 1999. Distribution patterns and zoogeography of Eumolpidae of Fujian Province, China (Coleoptera) [J]. Acta Zootaxonomica Sinica, 24(1): 65-74. [周红章. 1999. 福建省肖叶甲科属种分布类型与动物 地理格局. 动物分类学报, 24(1): 65-74.]

Zhou HZ. 1999. Regional and altitudinal differences in species distibution of Eumolpidae (Coleoptera) of Fujian Province, China [J]. Acta Zootaxonomica Sinica, 24(3): 320-330. [周红章. 1999. 福建省肖叶 甲科物种垂直分布与区域分化的比较研究(鞘翅目: 肖叶甲科). 动 物分类学报, 24(3): 320-330.]

附表 1 黑龙江省肖叶甲科亚科、属、种分布

Appendix 1 List of subfamilies, genera and species of Eumolpidae in Heilongjiang Province

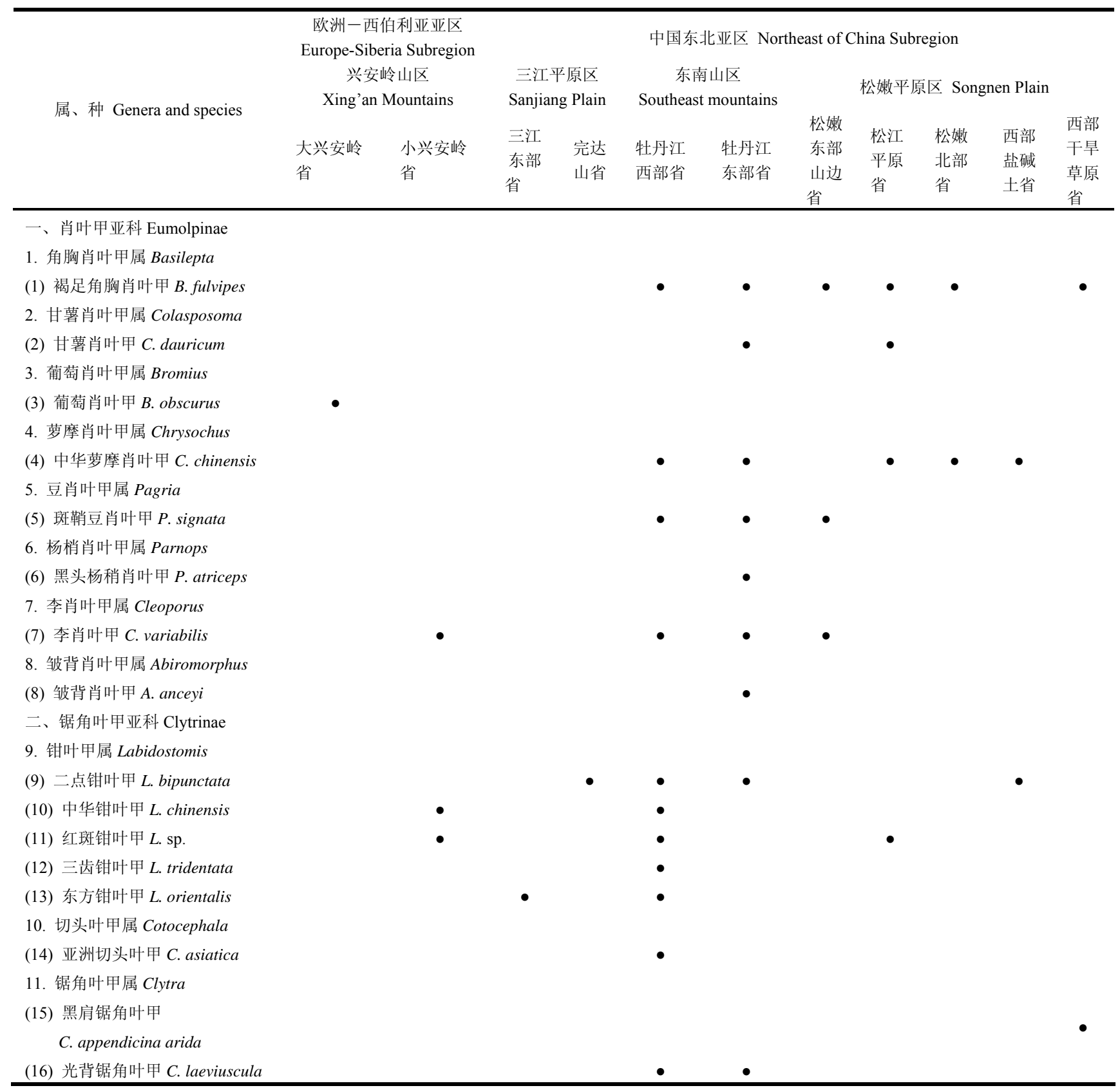


(接上表)

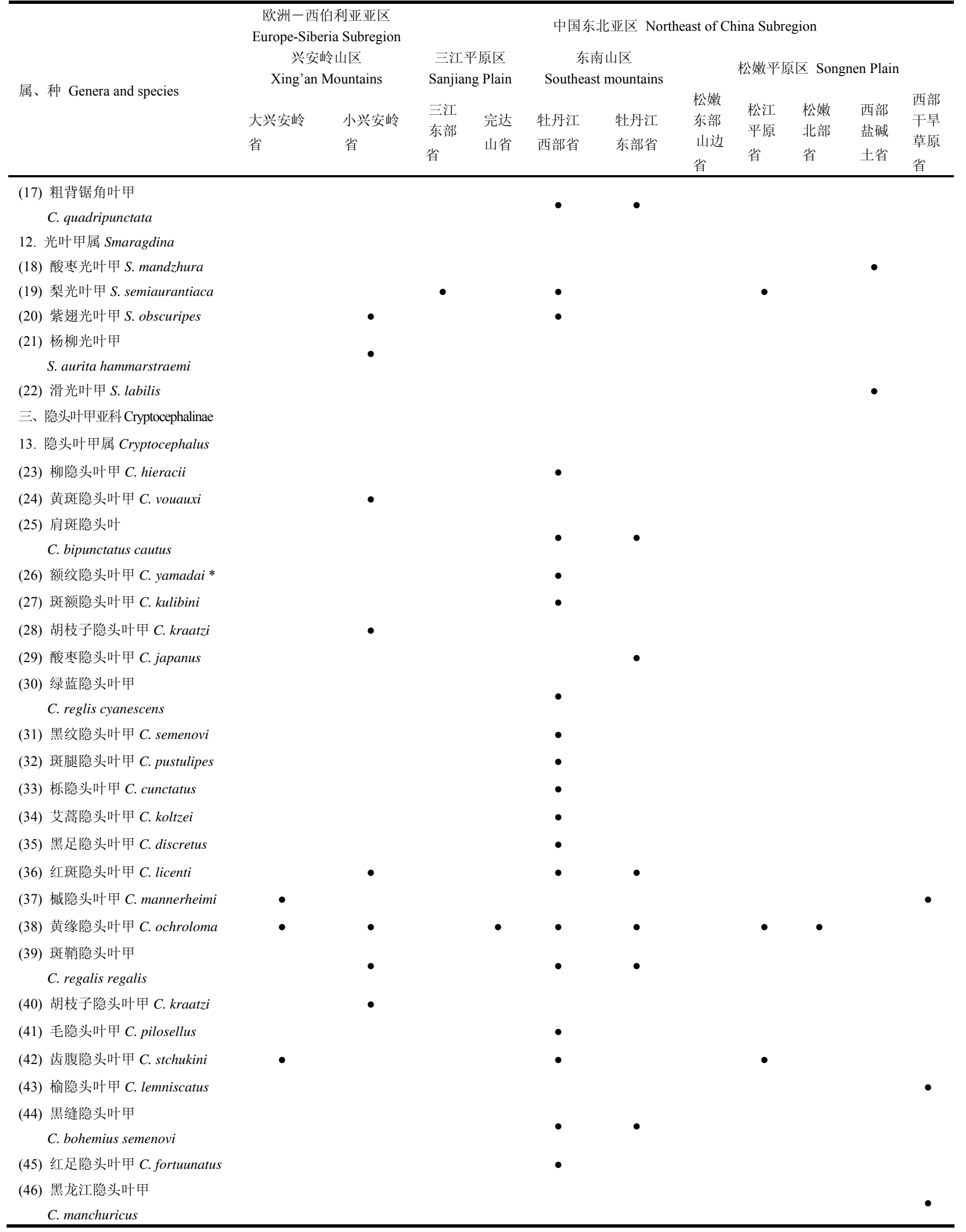


(接上表)

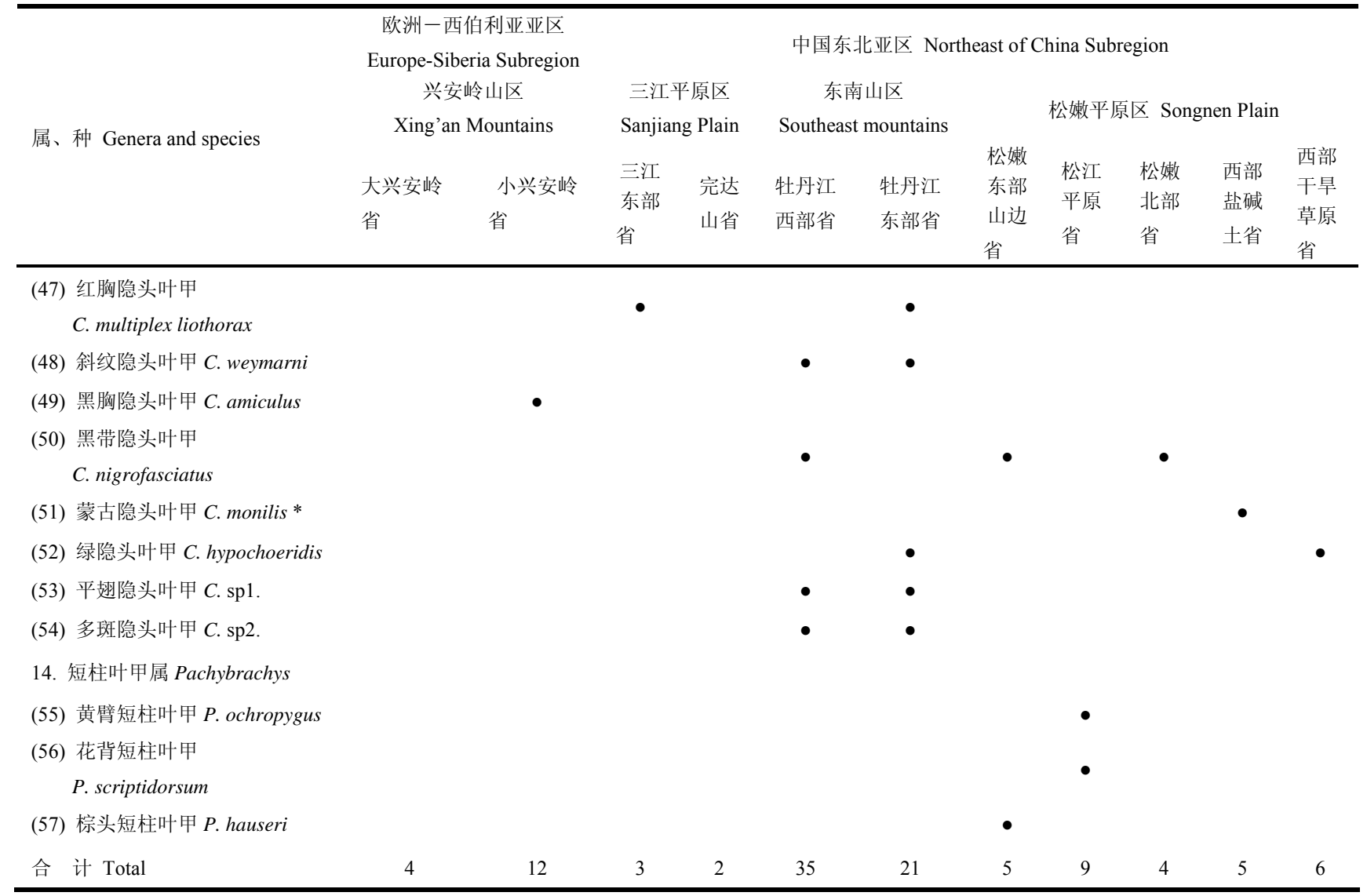

兴安岭山区 Xing'an Mountains; 三江平原区 Sanjiang Plain; 东南山区 Southeast mountains; 松嫩平原区 Songnen Plain; 大兴安岭省 Daxing'an Mountain Region; 小兴安岭省 Xiaoxing'an Mountain Region; 三江东部省 Eastern Sanjiang Region; 完达山省 Wandashan Region; 牡丹江西部省 Western Mudanjiang Region; 牡丹江东部省 Eastern Mudanjiang Region; 松嫩东部山边省 Eastern Songnen Region; 松江平原省 Songiiang plain Region; 松嫩北 部省 Northern Songnen Region; 西部盐碱土省Western salinization soil Region; 西部干早草原省 Western dry grasslands Region。

*代表中国新记录种, 红斑针叶甲 L. sp.、平翅隐头叶甲 C. sp1、多斑隐头叶甲 C. sp2. 为本次研究中发现的 3 个新种, 将另文发表。

${ }^{*}$ Represent new record species in China. L. sp, C. sp1 and C. sp2 are new species in this research, will release at others paper. 